\title{
Coeliac disease and autoimmunity
}

\author{
M. J. LANCASTER-SMITH* \\ B.Sc., M.B., B.S., M.R.C.P. \\ E. T. SWARBRICK \\ M.B., B.S., M.R.C.P.
}

\author{
J. PERRIN \\ M.D., M.R.C.P. \\ J. T. WRIGHT \\ D.M., F.R.C.P.
}

The Departments of Gastroenterology and Clinical Immunology, The London Hospital, London, E.1

\begin{abstract}
Summary
Among fifty-seven patients with proven coeliac disease three also had thyrotoxicosis, two insulin dependant diabetes, three fibrosing alveolitis and one each had vitiligo, rheumatoid arthritis and cryptogenic cirrhosis. Autoantibodies were demonstrated in twelve of thirty-one patients tested, seven of these twelve had one of the above associated conditions. Antireticulin antibodies were found in seven of twenty-three patients tested, and there was a significant association with dietary gluten. These findings appear to support that coeliac disease is associated with disturbed immunity and that a predisposition to autoimmunity may exist.
\end{abstract}

\section{Introduction}

Associations between diseases affecting different systems, in which immunological processes may be involved, are being recognized with increasing frequency. There have been reports of coeliac disease co-existing with conditions which are considered to be of an autoimmune aetiology such as Sjorgren's syndrome (Pittman and Holub, 1965), cirrhosis (Salem and Truelove, 1965; Clinicopathological Conference, 1970), Addison's disease (Goudie et at., 1969) ulcerative colitis (Salem and Truelove, 1965), autoimmune thyroid disease (Siurula, Varis and Lumberg, 1968; Heilesen et al., 1969; Kuitunen et al., 1971), diabetes mellitus (Visakorpi, 1969; Hoof et al., 1968), and interstitial lung disease (Hood and Mason, 1970; Lancaster-Smith, Benson and Strickland, 1971). These have mostly been reports of isolated cases and no attempts have been made to assess the frequency with which autoimmune diseases occur in adult coeliac disease. A recent study by Seah et al., 1971, suggests that autoantibodies do occur more frequently in adult coeliac disease than in a control population. We have therefore reviewed all of the patients with adult coeliac disease who attended The London Hospital during a

* Present Address: Department of Gastroenterology, St Bartholomew's Hospital, London, E.C.1. 5-year period, in an attempt to assess the prevalence of autoimmune phenomena in this group.

\section{Patients and methods}

The records of fifty-seven patients with adult coeliac disease who attended the hospital between 1967 and 1972 were reviewed. In all patients the diagnosis has been made by jejunal biopsy and all have at some time shown a significant response to gluten withdrawal. There were twenty-four males and thirty-three females with an average age of 46 (range 14-78). Note was taken of other diseases which might be considered to have an autoimmune basis. In such cases the diagnosis was further confirmed by interview, examination, investigation and information from other sources.

The sera of thirty-one of these patients were tested for the presence of autoantibodies. Seventeen were male, fourteen were female and twenty-one were on a gluten free diet. A group of thirty-one medical outpatients matched for sex and age acted as controls.

Antibodies sought were rheumatoid factor by the F.11 latex particle method, thyroglobulin antibody by tanned red cell haemagglutination (TTRC) (Fulthorpe et al., 1961) and antibodies against smooth muscle (SM), gastric parietal cells (GPC), thyroid microsomes (TM), nuclei (ANF) and mitochondria (Mit.) by immunofluorescence, with an initial 1 in 10 dilution of the patient's serum. Antireticulin antibody was looked for in twenty-three patients by the method of Seah et al. (1971).

\section{Results of clinical studies}

Eleven of fifty-seven patients $(19 \%)$ had evidence of past or present diseases which are considered to be of possible autoimmune aetiology. Three had a substantiated past history of thyrotoxicosis, three had pulmonary dysfunction considered to be due to fibrosing alveolitis and have been reported previously (Lancaster-Smith et al., 1971), two had insulin dependent diabetes mellitus, and vitiligo, cryptogenic 
TABLE 1. Auto antibodies in thirty-one patients with coeliac disease and thirty-one controls

\begin{tabular}{lccccccc}
\hline & F. 11 & TTRC & TM & GPC & ANF & FM & Mit. \\
\hline Coeliac patients & 3 & 5 & 4 & 1 & 3 & 4 & 0 \\
Controls & 1 & 1 & 1 & 0 & 1 & 1 & 0 \\
\hline
\end{tabular}

See Table 2 for explanation of abbreviations.

TABLE 2

\begin{tabular}{|c|c|c|c|c|c|}
\hline Case & Sex & $\begin{array}{l}\text { Present } \\
\text { age }\end{array}$ & $\begin{array}{l}\text { Age of onset } \\
\text { of coeliac } \\
\text { disease }\end{array}$ & Autoimmune disease & Autoantibodies in present study \\
\hline 1 & $\mathbf{F}$ & 52 & 48 & Age 31 -Thyrotoxicosis & TTRC $1: 320$ \\
\hline 2 & $\mathbf{F}$ & 55 & 16 & Age 38 - Thyrotoxicosis & ANF 1: 40 \\
\hline 3 & $\mathrm{~F}$ & 46 & 19 & Age 39-Thyrotoxicosis & $\begin{array}{l}\text { TTRC } 1: 80, \text { TM positive, } \\
\text { GPC positive }\end{array}$ \\
\hline 4 & $\mathbf{M}$ & 40 & 19 & Age 38 -Insulin dependent diabetes & TTRC $1: 20,000$, TM $1: 64$ \\
\hline 5 & $\mathbf{F}$ & 33 & 24 & Age 10 -Insulin dependent diabetes & ARA positive \\
\hline 6 & $\mathbf{M}$ & 59 & 52 & Age 58-Interstitial lung disease & $\begin{array}{l}\text { TTRC } 1: 4 \times 10^{6}, \text { TM } 1: 64 \text {, } \\
\text { ANF positive, SM positive, } \\
\text { ARA positive }\end{array}$ \\
\hline 7 & $\mathbf{M}$ & 67 & 64 & Age 66 -Interstitial lung disease & \\
\hline 8 & $\mathbf{M}$ & 55 & 31 & Age 53 -Interstitial lung disease & $\begin{array}{l}\text { TTRC } 1: 10,000, \text { ANF positive, } \\
\text { SM positive, ARA positive }\end{array}$ \\
\hline 9 & $\mathbf{F}$ & 62 & 40 & Age 40 -Progressive vitiligo & SM positive \\
\hline 10 & $\mathbf{M}$ & $69 *$ & 47 & $\begin{array}{l}\text { Age } 69-\text { Macronodular cirrhosis } \\
\text { S.M. positive }\end{array}$ & NT \\
\hline 11 & $\mathbf{F}$ & $49 *$ & 44 & $\begin{array}{l}\text { Age } 44-\text { Rheumatoid arthritis } \\
\text { Latex } 1: 320\end{array}$ & NT \\
\hline
\end{tabular}

* At death; NT, not tested; TTRC thyroglobulin tanned red cell haemagglutination; ANF antinuclear factor;

TM thyroid microsomal; GPC gastric parietal cell; ARA antireticulin; SM smooth muscle; Mit. mitochondrial.

cirrhosis, and rheumatoid arthritis were individually present in three patients (Table 2).

\section{Results of immunological studies}

Excluding antireticulin antibodies, twenty positive autoantibody tests were detected in twelve of the thirty-one patients tested (Table 2). Of these twelve patients seven are included in the group with associated diseases listed above (Table 2). Of the remaining five patients without other diseases, three had positive latex tests $(1 / 20,1 / 20,1 / 40)$, one had smooth muscle antibody and another thyroid microsomal antibody. Five of the controls gave positive tests (Table 1). This demonstrates a significantly increased incidence of autoantibodies in the coeliac group $(P<0.01)$.

Antireticulin antibody was found in seven of twenty-three patients tested. The antibody was of the IgG class in all cases but IgA antibody was also present in two patients. Of thirteen patients on a gluten free diet only one had antireticulin antibody, whilst of ten patients on a normal diet six had antibodies against reticulin $(P<0.05$ Fisher's exact test).

\section{Discussion}

In this group of fifty-seven patients with coeliac disease eleven $(19 \%)$ have a history of associated conditions for which there is evidence of an autoimmune aetiology. The aetiology of diabetes mellitus is unknown, but its association with established autoimmune disease (Carpenter et al., 1964), the increased prevalence of autoantibodies in insulin requiring diabetes (Irvine et al., 1970) and lymphocytic infiltration of pancreatic islets (Gepts, 1965), suggest that autoimmune mechanisms may be involved. The concurrence of diabetes and villous atrophy of the jejunum has been reported in other communications (Visakorpi, 1969; Hoof et al., 1968). Coeliac syndrome has also been found in association with autoimmune thyroid disease on previous occasions (Siurula, Varis and Lamberg, 1969; Heilesen et al., 1969; Kuitunen et al., 1971). The patients with evidence of interstitial lung disease (Lancaster-Smith et al., 1971) were thought to represent examples of intrinsic fibrosing alveolitis, a condition with many autoimmune markers (Mackay and Ritchie, 1965). Rheumatoid arthritis is generally considered to have an autoimmune basis and vitiligo is often associated with autoimmune disorders (Editorial, 1971). An autoimmune aetiology has been proposed for some cases of cryptogenic cirrhosis (Doniach and Walker, 1969), although the aetiology of our patient's liver disease 
is not clear. Patients with concurrent coeliac disease and cirrhosis have been reported (Salem and Truelove, 1965; Clinicopathological Conference, 1970).

The proportion of positive autoantibody tests found in this study is comparable to that found by Seah et al. (1971), but our group of thirty-one patients included seven with other disorders who accounted for fifteen of the twenty tests (Table 2).

Coeliac disease has been described by Hobbs as a 'localized dysgammaglobulinaemia' as evidenced by an abnormal plasma cell population of the jejunum and immunoglobulin concentrations in the jejunal juice (Douglas, Crabbé and Hobbs, 1970). It has also been proposed that the IgA response is qualitatively inadequate (Hobbs, 1971). Generalized IgA deficiency is associated with autoimmune disease (Hobbs, 1968), and is also found in 3\% of coeliacs (Hobbs, 1971). Thus, although the majority of patients with coeliac disease, like those in the present study, do not have IgA deficiency, the local and qualitative disturbance which is apparently common in the coeliac subject might in the same way predispose to autoimmune processes.

Disturbed cell mediated immunity as reflected by abnormal leucocyte migration (Pagaltsos et al., 1971) and lymphocyte transformation (Blecher et al., 1969) occurs in coeliac disease and may play a part in the pathogenesis of autoimmunity. More recently Fakhri and Hobbs (1972) suggested that the 'nonimmune' lymphocyte might be involved in the development of both coeliac disease and autoimmune conditions such as thyroiditis. It is possible in a minority of cases more than one target tissue could be involved in the same patient.

The demonstration of antireticulin antibodies in $30 \%$ of our patients is comparable to the $34 \%$ previously reported by Seah et al. (1971). Alp and Wright (1971) found this antibody in $37 \%$ of adult coeliacs and demonstrated an association with dietary gluten which we were able to confirm by this present study. The significance of antibodies against reticulin is obscure. Seah believes that they may indicate a primary defect in the subepithelial tissues of the jejunal mucosa. Their presence in $25 \%$ of Crohn's patients, however, implies that they may be raised in response to non-specific intestinal mucosal injury, but perhaps subsequently having a secondary pathogenic role (Alp and Wright, 1971). On the other hand, if autoimmune processes do occur more frequently in coeliac disease, antireticulin antibody may merely reflect a tendency to form autoantibodies, in this instance as a response to the external agency of gluten.

It is impossible to say whether the finding of 'autoimmune disease' in $19 \%$ of our patients is anything more than fortuitous. Nevertheless, we feel that this, together with the previous reports and the incidence of tissue antibodies found in this and other studies, raises the possibility that an association may exist between coeliac and autoimmune diseases.

\section{Acknowledgments}

We wish to thank Dr E. J. Holborow for his advice on the interpretation of and for performing some of the antireticulin antibody tests; Dr S. Farrow for his assistance with the statistical analysis and the physicians of The London Hospital for allowing us to study their patients.

\section{References}

AlP, M.H. \& Wright, R. (1971) Autoantibodies to reticulin in patients with idiopathic steatorrhoea, coeliac disease, and Crohn's disease, and their relation to immunoglobulins and dietary antibodies. Lancet, ii, 682.

Blecher, T.E., BrechWa-AdJukiewicz, A., McCarthy, C.F. \& READ, A.E. (1969) Serum immunoglobulins and lymphocyte transformation studies in coeliac disease. Gut, $10,57$.

Carpenter, C.C.H., Solomon, N., Silverberg, S.G., Bledsoe, T., NorthCutt, R.C., Klinenberg, J.R., BenNetT, I.L. \& McGehee Harvey, A. (1964) Schmidt's syndrome (thyroid and adrenal insufficiency). A review of the literature and a report of fifteen new cases including ten instances of co-existing diabetes mellitus. Medicine (Baltimore), 43, 153.

Clinicopathological Conference (1970) A Case of Malabsorption, Intestinal Mucosal Atrophy and Ulceration, Cirrhosis, and Emphysema. British Medical Journal, 3, 207.

Doniach, D. \& Walker, J.G. (1969) A unified concept of autoimmune hepatitis. Lancet, i, 813.

Douglas, A.P., Crabbé, P.A. \& HobBS, J.R. (1970) Immunochemical studies of the serum, intestinal secretions and intestinal mucosa in patients with adult celiac disease and other forms of the celiac syndrome. Gastroenterology, 59, 414.

EdITORIAL (1971) Vitiligo. Lancet, ii, 1298.

FAKHRI, O. \& HoBBS, J.R. (1972) Detection of antibodies which can co-operate with lymphocytes. Lancet, ii, 403.

Fulthorpe, A.J., Roitt, I.M., Doniach, D. \& Couchman, K. (1961) A stable sheepcell preparation of dietary thryoglobulin autoantibodies and its clinical application. Journal of Clinical Pathology, 14, 654.

GePts, W. (1965) Pathological anatomy of the pancreas in juvenile diabetes mellitus. Diabetes, 14, 619.

Goudie, R.B., Boyle, I.T., Stuart-Smith, D.A. \& FerGUSON, A. (1969) Serological diagnosis of idiopathic Addison's disease in patients on prolonged prednisolone therapy for steatorrhoea. Lancet, i, 186.

Heilesen, C., Friss, T., Larsen, E. \& Pock-Steen, O.C. (1969) Small intestinal histology, radiology and absorption in hyperthyroidism. Scandinavian Journal of Gastroentero$\log y, 4,169$.

HоввS, J. (1968) Immune imbalance in dysgammaglobulinaemia type IV. Lancet, i, 110.

Hоввs, J. (1971) Immunological disturbances in the pathogenesis of malabsorption. Journal of Clinical Pathology. 24 Suppl. (Royal College of Pathologists), 5, 146.

Hood, J. \& Mason, A.M.S. (1970) Diffuse pulmonary disease with transfer defect occurring with coeliac disease. Lancet, i, 445.

Hoof, C., Devos, E., Kriekemanns, J. \& van Damme, J. (1968) Malabsorption and diabetes mellitus in children. Helvetica Paediatrica Acta, 5, 478. 
Irvine, W.J., Clark, B.F., Scarth, L., Cullen, D.R. \& DunCAN, L.J.P. (1970) Autoantibodies in diabetes mellitus. Lancet, ii, 163.

Kuitunen, P., Maenpua, J., Krohn, K. \& Viskorpi, J.K. (1971) Gastrointestinal findings in autoimmune thyroiditis and non-goitrous juvenile hypothyroidism in children. Scandinavian Journal of Gastroenterology, 6, 335.

LANCASTER-Smith, M.J., Benson, M.K. \& Strickland, I.D. (1971) Coeliac disease and diffuse interstitial lung disease. Lancet, $\mathbf{i}, 473$.

MaCKay, I.R. \& Ritchie, B. (1965) Diffuse fibrosing alveolitis, two cases with autoimmune features. Thorax, 20, 200.

Pagaltsos, A.S., Kumar, P.J., Willoughby, J.T.M. \& DAwson, A.M. (1971) In vitro inhibition of leucocyte migration by sarcoid spleen suspension in coeliac disease and dermatitis herpetiformis. Lancet, ii, 1179.

Pittman, F.E. \& Holub, D.A. (1965) Sjögren's Syndrome and adult celiac disease. Gastroenterology, 48, 869.

Salem, S.N. \& Truelove, S.C. (1965) Small-intestinal and gastric abnormalities in ulcerative colitis. British Medical Journal, 1, 827.

Seah, P.A., Fry, L., Hoffbrand, A.V. \& Holborow, E.J. (1971) Tissue antibodies in dermatitis herpetiformis and adult coeliac disease. Lancet, i, 834.

Siurula, M., VARIS, K. \& LAMberG, B.A. (1968) Intestinal absorption and autoimmunity in endocrine disorders. Acta Medica Scandinavica, 184, 53.

VISAKORPI, J.K. (1969) Diabetes and coeliac disease. Lancet, ii, 1192.

Postgraduate Medical Journal (Januasy 1974) 50, 48-50.

\section{Solitary cyst of the liver presenting as an abdominal emergency}

\author{
S. C. SoOD \\ F.R.C.S.
}

\author{
A. WATSON* \\ F.R.C.S.
}

\section{Department of Surgery, Maelor General Hospital, Wrexham}

\section{Summary}

A case of torsion of a solitary non-parasitic cyst of the liver presenting as an acute abdominal emergency is described. Reference is made to the pathogenesis of such cysts, which occur infrequently and only rarely present with complications. A review of previous reports of complications in such cysts is presented.

\section{Introduction}

Non-parasitic cysts of the liver are relatively uncommon, and are usually discovered as incidental findings at laparotomy. Complications arising in such cysts are rare, but occasional reports of these have occurred in the literature. Rupture into the peritoneal cavity (Horton, 1954), intracystic haemorrhage (Ackman and Rhea, 1931) and strangulation (Orr and Thurston, 1927; Grime et al., 1959) have been described presenting as an acute abdominal emergency. We report a case of a solitary non-parasitic cyst arising from the liver having undergone sudden spontaneous torsion on a pedicle and presenting as an acute abdominal emergency.

\section{Case report}

An 18-year-old unmarried girl was admitted to the Surgical Unit from the Casualty Department having collapsed with severe abdominal pain. She was watching television when she experienced sudden agonizing pain in the abdomen, and was able to

* Present address: University Hospital of Wales, Cardiff. obtain some relief by crouching or lying on her left side. Earlier that day, she had felt miserable and experienced a tingling discomfort in the abdomen from time to time. Shortly before the onset of pain she had a bowel action and felt nauseated, but did not vomit. The patient had previously noted some abdominal fullness, but attributed this to a possible pregnancy. On admission she was pale and restless. Her pulse rate was $110 / \mathrm{min}$, temperature $36^{\circ} \mathrm{C}$ and blood pressure $120 / 80 \mathrm{~mm} \mathrm{Hg}$. There was a noticeable swelling in the lower abdomen in an otherwise thin patient. The swelling was mobile, tender, dull to percussion and appeared to arise from the pelvis. Pelvic examination revealed a large cystic mass anterior to a normal sized uterus. Initial investigations revealed a haemoglobin of $12.1 \mathrm{~g} / 100 \mathrm{ml}$ and a white cell count of $17,400 / \mathrm{cc}$. The most likely diagnosis was thought to be acute torsion of an ovarian cyst, and she was prepared for laparotomy. Laparotomy was performed through a right paramedian incision. An enormous and apparently multi-loculated cyst was revealed on opening the abdomen, and the whole cyst was congested and dusky with evidence of haemorrhage within it. The appearances were interpreted as being indicative of torsion, but no pedicle was found in the pelvic cavity. On further examination, the pedicle was found to be arising from the upper abdomen, and was traced to an accessory process of liver tissue, arising just to the left of the ligamentum teres. Torsion about this pedicle had occurred, and after reducing the 